\title{
Modeling and Evaluation of E-Voting System for a Sustainable Credible Election
}

\author{
Ajiboye Adeleke R. \\ Dept. of Computer Sc. \\ University of llorin, llorin. \\ Jimoh Rasheed G. \\ Dept. of Computer Sc. \\ University of llorin, llorin
}

\author{
Adewole Kayode S. \\ Dept. of Computer Sc. \\ University of llorin, llorin. \\ Oladipo Idowu D. \\ Dept. of Civil Engineering \\ University of llorin, llorin
}

\begin{abstract}
Voting is an action considered to be fundamental in a democratic setting. E-voting can be referred to as an election that involves using an electronic device for the purpose of casting votes. Lack of transparency and other problems associated with semi-manual method of casting vote in Nigeria has indeed called for a more robust electronic voting system. In this paper, a model for evaluating e-voting system using fuzzy logic approach is proposed. The model was simulated and tested for students' union election using a Federal University in Nigeria. Opinions of the students regarding the proposed model were randomly sampled and analyzed for the purpose of evaluation especially when compared with the existing system of voting. Furthermore, factors that can guarantee free and fair election were discussed and put into consideration during the development of the model. The result shows that the proposed model was effective, efficient and reliable for implementing electronic voting system.
\end{abstract}

\section{General Terms}

Modeling, E-voting, Fuzzy logic.

\section{Keywords}

E-voting, democracy, UML, fuzzy-logic, election.

\section{INTRODUCTION}

E-voting refers to an election that involves the use of electronic means in at least the casting of the vote [11]. Voting is a process that takes an important position in a democratic society. Recently, its adoption in institutions of higher learning among students for electing their leaders is gaining popularity as electronic voting (e-voting) brings to the polling station. Several advantages were noted in [6], such merits were listed as improved turn out, accessibility for impaired people, and improved accuracy and speed. The introduction of e-voting raises some of the same challenges faced when applying electronics to any other subject, for example e-government [11]. It is a fundamental rite of individual to vote, as this is to prevent unwanted politicians from gaining access to the position of governance, choose new representatives, and take a stand on important issues. According to [8], democracy is more than votes - it is an expression of what one intends to do through documentation, campaigning and liaising with people in general. Through the long history of democracy, in the pursuit of power, some groups are willing to threaten voters in order to intimidate them; the only way to avoid intimidation is to adopt secret ballot system, this make threat during voting period to become useless [8].

The open rights group in 2007 opined that for an election to be considered free and fair, it is expected to meet some international standards; those listed include accuracy, security and verifiability. Also, voters are only allowed one anonymous ballot each, which they can mark in privacy [8].

For an election to withstand the test of time, it must be robust and be ready to withstand a variety of fraudulent behaviors. It must also be sufficiently transparent and comprehensible so that voters and losers can accept the results of the election [12].

Formerly when elections were made traditionally, organizers determine who is eligible to vote and who should not even move close to polling stations. This may involve a formal registration period or making a formal announcement of age of voters or other factors that may make one eligible to vote. Once the election begins, the administrator may validate the credentials of those attempting to vote [3]. In contrary to the traditional way of voting, electronic voting is essential because it considers ways in which the polling tasks can be performed electronically without sacrificing voter privacy or introducing opportunities for fraud. In order to determine whether a system performs these tasks well, it is useful however, to develop a set of criteria for evaluating system performance. The criteria to be developed are such as accuracy, democracy, convenience, flexibility, privacy, verifiability and mobility [7]. The adoption of e-voting in institution of higher learning is a welcome development as students would have the opportunity of electing their representative within a very short time with high degree of credibility. The proposed model therefore, focuses on evaluating the metrics that are considered as vital to any election system.

\section{EXISTING E-VOTING TOOLS AND RELATED WORKS}

The different types of electronic tools which can be used in elections were identified in [11], typical among them are:

- Direct Recording Electronic computers (DREs). Here, computers can be installed at a polling station for recording and storing the votes cast. The casting of vote may involve the use of touch screen (with or without a specific pen) or through the use of other devices by pressing one or more buttons; 

network medium is guaranteed for casting of votes like a polling station or in a non-controlled area such as a kiosk or the home;

- Optical and digital scanning devices are suitable for use in places such as designated counting area to scan ballot papers. These are normally used to improve the accuracy of the counting process and reduce potential manual counting errors; and

- The use of one medium to record the vote, which is then registered in a ballot box on another device at the polling station. This system differs substantially from a DRE as nothing is stored in the DRE and it is impossible for a voter to manipulate the memory containing the vote.

It was observed in [14] that residual vote is an aspect of election-system risk while others that mostly not considered to be less important are the potential for tampering and failure of the system. In addressing this type of challenge, [15] is of the opinion that systems should be designed not only with an emphasis on prevention, but also with an assumption that prevention will fail and countermeasures will be needed as well-designed systems is expected to fail smartly. However, [15] describes systems that fail badly as brittle and systems that fail well as resilient.

Comparative perspective carried out on e-voting in [13] shows that majority of the voters interviewed voted using e-voting because it was convenient and traditional voters were of the opinion that it was hardware barriers that scare them from electronic voting. It was also established in [13] that lack of a card reader, electronic ID card, Internet connection, or a computer accounted for more than half of all reasons why individuals did not vote using the Internet.
- Online voting which can be done where a reliable

\section{DESIGN AND METHODOLOGY}

A good programming practice requires proper designing of processes involved in building a software model. Design is first concern with specification of a software architecture that defines major software components and their relationships. Design also involves reaching a balance between requirements that conflict with each other within implementation environment constraints [10]. Several tools may be used to model software in the process of software design, typical among them is Unified Modeling Language (UML).

\subsection{Unified Modeling Language (UML)}

The Unified Modeling Language (UML) is a visual, objectoriented, and multi-purpose modeling language. UML emerged from the intention of Rumbaugh, Booch, and Jacobson to find a common framework for their approaches and notations [4]. With UML, it is possible to model the types, properties, and states of objects as well as to integrate corresponding object flows into the activities. According to [10], a model is an abstraction of the physical system with a certain purpose; a useful model has just the right amount of detail and represents only what is important for the task at hand. The heart of UML's usefulness lies in its diagrams. [9] identified nine major types of these diagrams as: Class diagrams, Object diagrams, Collaboration diagrams, Sequence diagrams, Activity diagrams, State chart diagrams, Component diagrams, Deployment diagrams and Use case diagrams. Activity and state chart diagrams, as well as sequence and collaboration diagrams are semantically equivalent, in other words, these diagrams display the same information; however, having them separate is important because of the difficulty to conceptualize the material contained in both. Providing two separate viewpoints helps to shed more light on all facet of the system. In this paper, activity and use case diagrams were used as the fundamental tool for process modeling with UML.
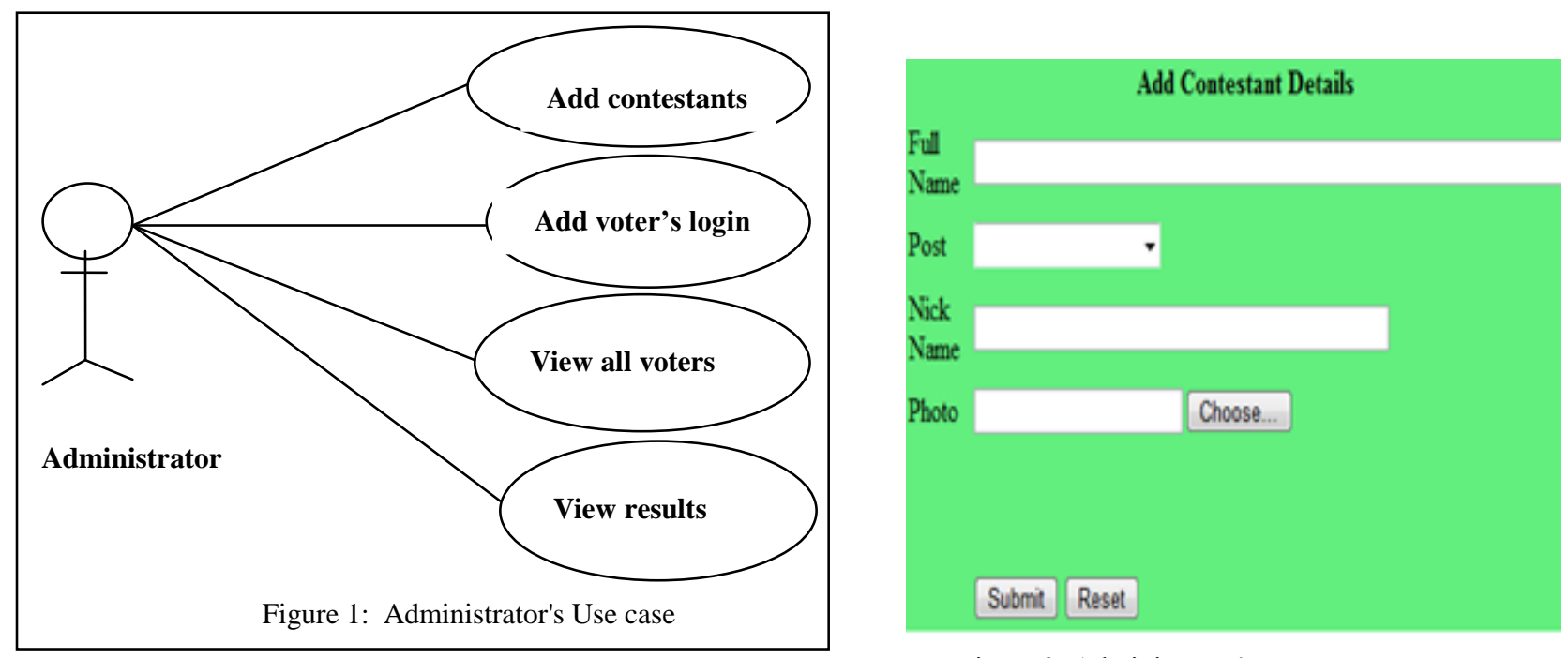

Figure 2: Administrator's screen

user friendly, robust and dynamic. The figure below shows the activity diagram of the proposed system:
The design was implemented using PHP and MySql database as back-end with much concentration on making the software 


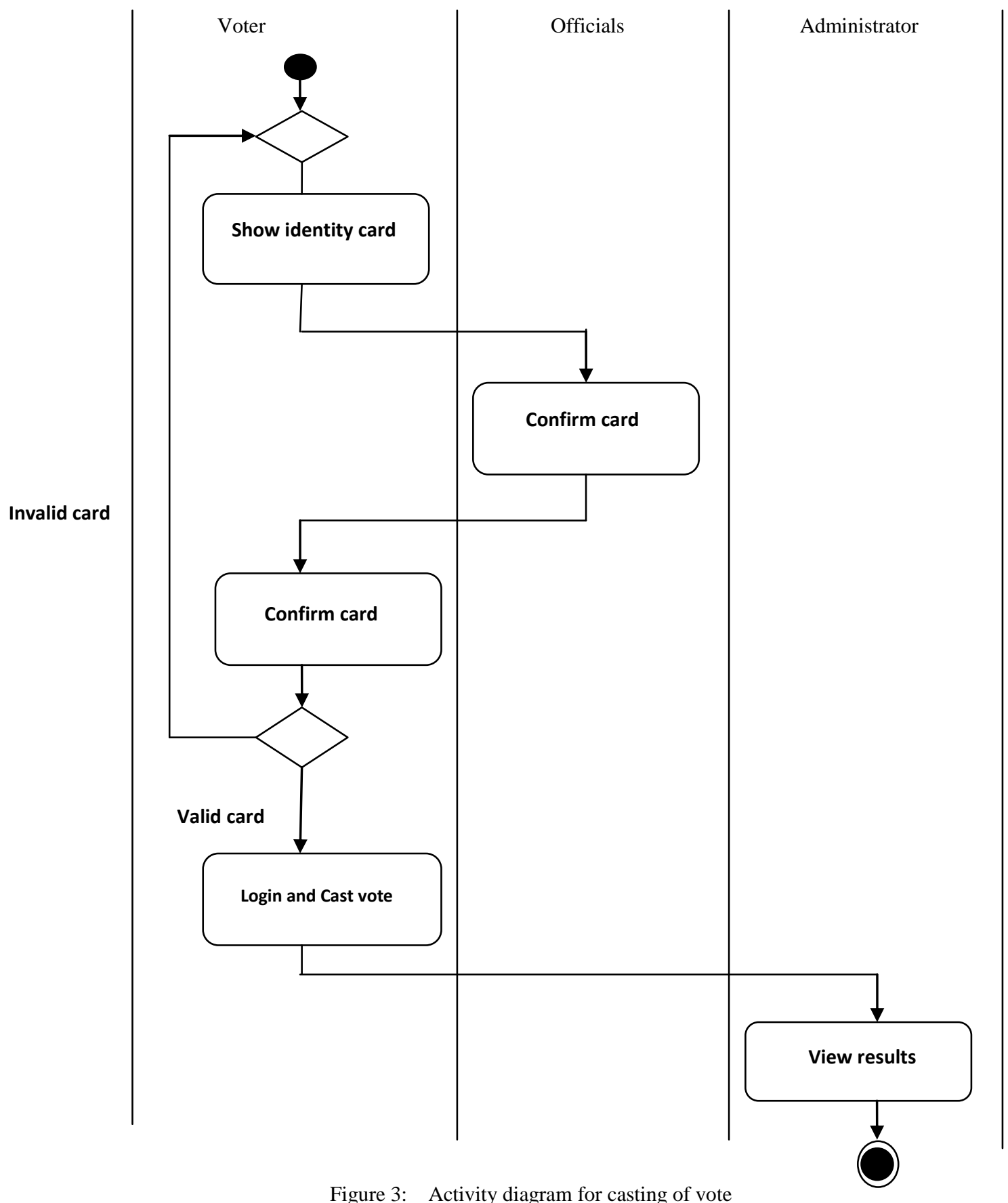

Figure 3: Activity diagram for casting of vote

\subsection{Fuzzy logic}

Fuzzy set is an extension of the concept of an ordinary set usually referred to as crisp set. For a crisp set $\mathrm{X}$, an element either belongs to $\mathrm{X}$, represented by logic 1 , or does not, represented by logic 0 [2]. The fuzzy linguistics variable "standard" can be categorized as: below minimum, minimum, above minimum, normal and best. Each category is called a linguistic modifier. This modifier is linked to a numeric value on a scale as shown in figure 4 . The scale ranges from 0 to 7 and fuzzy sets are used to characterize the software application (below minimum standard, minimum standard, above minimum standard, normal standard and best standard). On the scale, the membership value of each linguistic modifier has a real number in the closed interval $[0,1]$. The fuzzy linguistic variable "standard" here denotes e-voting software application standard. Figure 4 represents a typical way of constructing fuzzy sets for linguistic variables where five fuzzy sets are used to evaluate the standardization of the software developed for evoting.

\subsubsection{Analysis of fuzzy sets structure and operations}

It was established in [1] that given a fuzzy set A in a universe $\mathrm{X}$, 
$A=\left\{x, \mu_{A}(x) \mid x \varepsilon X\right\}$

Where $\mu_{A}(x)$ represents the grade of membership or compatibility function of element $x$ of $X$ in fuzzy set A. Element $X$ may show a full, partial or no membership in A. Its membership grade would be considered to be full if $\mu_{A}(x)=1$; partial if $\mu_{A}(x)$ lies between 0 and 1 i.e $0<\mu_{A}(x)<1$; and there is no membership if $\mu_{A}(x)=0$. A fuzzy set is therefore formed when a linguistic variable is combined with a linguistic modifier (i.e. minimum standard, below minimum standard, normal standard etc).

The interpretations of the five fuzzy sets are as follows:

below_minimum_standard $=\{0|0.3,1| 0.4,2|0.7,3| 0.0,4 \mid 0.0$, $5|0.0,6| 0.0,7 \mid 0.0\}$

minimum_standard $=\{0|0.0,1| 0.2,2|0.5,3| 0.8,4|0.0,5| 0.0$, $6|0.0,7| 0.0\}$

above_minimum_standard $=\{0|0.0,1| 0.0,2|0.3,3| 0.6,4 \mid 0.7$, $5|1.0,6| 0.0,7 \mid 0.0\}$

normal_standard $=\{0|0.0,1| 0.0,2|0.0,3| 0.0,4|0.5,5| 0.6,6 \mid 0.7$, $7 \mid 1.0\}$

best_standard $=\{0|0.0,1| 0.0,2|0.0,3| 0.0,4|0.0,5| 0.0,6 \mid 0.5$, $7 \mid 0.8\}$

Each linguistic modifier is linked to a numerical value on a scale ranges from 0 to 7 that represents the standardization of the software. Also, each element represents a corresponding value of a degree of membership in the universe of discourse.

Fuzzy sets can be manipulated using one of the four standard fuzzy set operations: union, intersection, complementation, and implication operations [5]. However, fuzzy set operations are not limited to these four. A fuzzy set union is performed by applying the maximum (Max) function to the elements of two sets, for instance, let

$\mu_{A}(x)=\{1,4,6,8,9\}$ and $\mu_{B}(y)=\{1,2,3,9,9\}$ the union of fuzzy set $C=A \cup B$; it follows that:

$\mu_{C}(z)=\mu_{A} \cup \mu_{B}(z)$

$\mu_{C}(z)=\{1,4,6,9,9\}$.

$\mu_{A} \cap \mu_{B}(k)=\{0,2,3,8,0\}$

The complement of a set is computed by subtracting each element of the set from its maximum possible value:

$\mu_{\bar{A}}(x)=\left\{9-\mu_{A}(x)=\{8,5,3,1,0\}\right.$

The implication function is employed to decide if a particular set is true, to what extent does it implies the other set can be said to be true? Implication operation can be illustrated by computing

$$
\mu_{\bar{A}} \cup \mu_{B}(q)=\mu_{\bar{A}}(x) \cup \mu_{B}(y)
$$$$
\mu_{\bar{A}}(x) \cup \mu_{B}(q)=\{8,5,3,1,0\} \cup\{1,2,3,9,9\} \quad=
$$
$\{8,5,3,9,9\}$

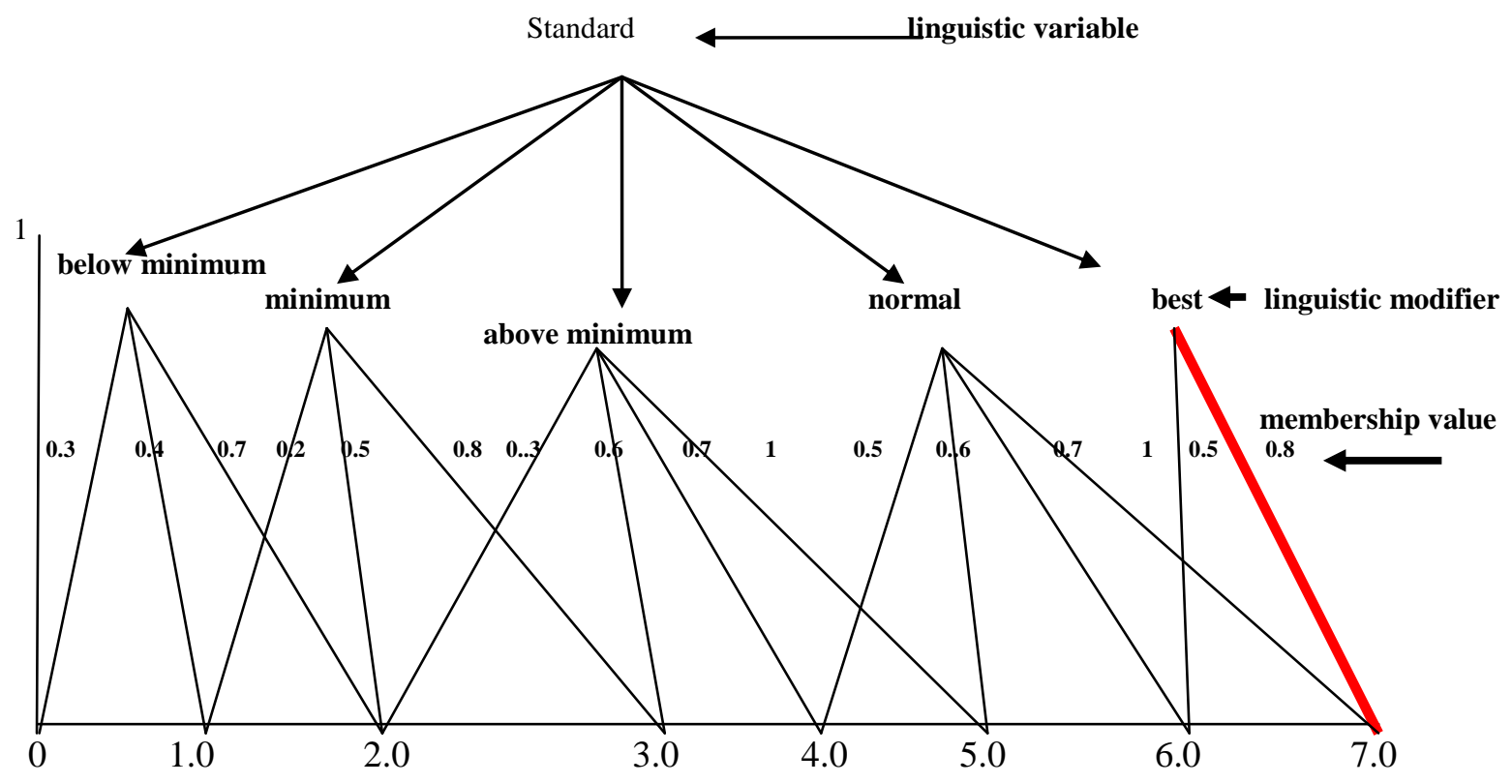

Figure 4: Fuzzy set structure of standard rating 
Table 1: Fuzzy linguistic variables and membership grades

\begin{tabular}{|l|l|}
\hline \multicolumn{1}{|c|}{ Linguistic Variables } & Fuzzy Values \\
\hline Below minimum standard & $0<=\mathrm{x}<=2.0$ \\
\hline Minimum standard & $1.0<=\mathrm{x}<=3.0$ \\
\hline Above minimum standard & $2.0<=\mathrm{x}<=5.0$ \\
\hline Normal standard & $4.0<=\mathrm{x}<=7.0$ \\
\hline Best standard & $6.0<=\mathrm{x}<=7.0$ \\
\hline
\end{tabular}

\subsubsection{Modeling the evaluation of e-voting software application standard}

In the proposed model, eleven Departments $(\mathrm{d} 1, \mathrm{~d} 2 \ldots . . \mathrm{d} 11)$ and five metrics (m1, m2 ...m5) were taking into consideration. Fuzzy logic approach was used with a view to arriving at a reasonable method for evaluating the standardization of e-voting software application developed for use in institution of higher learning for students' unionism. Fuzzy set A was therefore formed which takes values from set $\mathrm{X}$ in a closed interval $[0,1]$. From eqn. (1),

$$
f A(x)=\{0.2,0.3,0.4,0.5,0.6,0.7,0.8,0.9,1.0\}
$$

Table 2: Evaluation metrics

\begin{tabular}{|l|c|c|}
\hline Evaluation metrics & Representation & $\begin{array}{l}\text { Relative } \\
\text { importance }\end{array}$ \\
\hline Security compliance & E1 & 1 \\
\hline User friendliness & E2 & 0.7 \\
\hline Dependability & E3 & 0.6 \\
\hline $\begin{array}{l}\text { Platform } \\
\text { compatibility }\end{array}$ & E4 & 0.3 \\
\hline Robustness & E5 & 0.2 \\
\hline
\end{tabular}

Table 2 shows the evaluation metrics and their corresponding relative importance. The numerical value is the membership grade assigned to each metric and ranges between 0 and 1 .

Table 3: Linguistic variables

\begin{tabular}{|c|c|l|}
\hline $\begin{array}{l}\text { Relative } \\
\text { importance }\end{array}$ & Symbols & Linguistics variables \\
\hline 0.1 & us & $\begin{array}{l}\text { Unacceptable } \\
\text { standard }\end{array}$ \\
\hline 0.2 & $\mathrm{bms}$ & $\begin{array}{l}\text { Below minimum } \\
\text { standard }\end{array}$ \\
\hline 0.4 & $\mathrm{~ms}$ & Minimum standard \\
\hline 0.6 & $\mathrm{ams}$ & $\begin{array}{l}\text { Above minimum } \\
\text { standard }\end{array}$ \\
\hline 0.7 & $\mathrm{~ns}$ & Normal standard \\
\hline 1.0 & $\mathrm{bs}$ & Best standard \\
\hline
\end{tabular}

The linguistic variables are symbolized with two or more letters in table 3 and each variable assigned a numerical value within a closed value $[0,1]$. This denotes the relative importance of each linguistic variable.

Table 4: E-voting software standard rating across the selected Departments

\begin{tabular}{|l|l|l|l|l|l|l|l|l|l|l|l|}
\hline & D1 & D2 & D3 & D4 & D5 & D6 & D7 & D8 & D9 & D10 & D11 \\
\hline E1 & $\mathrm{ms}$ & ams & ms & ns & ams & ms & ams & ms & ns & ms & ns \\
\hline E2 & $\mathrm{ns}$ & $\mathrm{ms}$ & $\mathrm{ams}$ & $\mathrm{ms}$ & $\mathrm{ns}$ & $\mathrm{ns}$ & $\mathrm{ms}$ & $\mathrm{ns}$ & $\mathrm{bs}$ & ams & ams \\
\hline E3 & $\mathrm{ns}$ & $\mathrm{ns}$ & $\mathrm{ms}$ & $\mathrm{ams}$ & $\mathrm{ns}$ & $\mathrm{bs}$ & $\mathrm{ams}$ & $\mathrm{ams}$ & $\mathrm{ns}$ & $\mathrm{ns}$ & ams \\
\hline E4 & $\mathrm{ms}$ & $\mathrm{ams}$ & $\mathrm{ns}$ & $\mathrm{ams}$ & $\mathrm{ams}$ & $\mathrm{ms}$ & $\mathrm{ns}$ & $\mathrm{ms}$ & $\mathrm{ns}$ & ams & $\mathrm{ns}$ \\
\hline E5 & $\mathrm{ns}$ & $\mathrm{bs}$ & $\mathrm{ams}$ & $\mathrm{ns}$ & $\mathrm{bs}$ & $\mathrm{ns}$ & $\mathrm{ams}$ & $\mathrm{ns}$ & $\mathrm{bs}$ & $\mathrm{ns}$ & ams \\
\hline
\end{tabular}

The opinions of students regarding the system were randomly sampled, opinion that has highest frequency in respect of each metric (which reflect the general opinion of students) are recorded as shown in table 4 .

Table 5: E-voting software standard rating across the selected Departments

\begin{tabular}{|l|l|l|l|l|l|l|l|l|l|l|l|}
\hline & $\mathrm{D} 1$ & $\mathrm{D} 2$ & $\mathrm{D} 3$ & $\mathrm{D} 4$ & $\mathrm{D} 5$ & $\mathrm{D} 6$ & $\mathrm{D} 7$ & $\mathrm{D} 8$ & $\mathrm{D} 9$ & D10 & D11 \\
\hline E1 & 0.4 & 0.6 & 0.4 & 0.7 & 0.6 & 0.4 & 0.6 & 0.4 & 0.7 & 0.4 & 0.7 \\
\hline E2 & 0.7 & 0.4 & 0.6 & 0.4 & 0.7 & 0.7 & 0.4 & 0.7 & 1.0 & 0.6 & 0.6 \\
\hline E3 & 0.7 & 0.7 & 0.4 & 0.6 & 0.7 & 1.0 & 6.0 & 6.0 & 7.0 & 7.0 & 6.0 \\
\hline E4 & 0.4 & 0.6 & 0.7 & 0.6 & 0.6 & 0.4 & 0.7 & 0.6 & 0.7 & 0.6 & 0.7 \\
\hline E5 & 0.7 & 1.0 & 0.6 & 0.7 & 1.0 & 1.0 & 0.6 & 0.7 & 1.0 & 0.7 & 0.6 \\
\hline
\end{tabular}

In table 5, the numerical value replaces the linguistic variable symbols in table 4 . The table gives the relative importance of metrics 1 to 5 across the eleven Departments where the opinions were sampled.

\subsubsection{Collection of data}

The data collection form below was used to capture the opinions of students across the selected departments. 
Table 6: Data collection

\begin{tabular}{|l|l|l|l|l|l|}
\hline Department & $\begin{array}{l}\text { E1(Security } \\
\text { compliance) }\end{array}$ & $\begin{array}{l}\text { E2(User } \\
\text { friendliness) }\end{array}$ & $\begin{array}{l}\text { E3(Dependabil } \\
\text { ity) }\end{array}$ & $\begin{array}{l}\text { E4(Platform } \\
\text { compatibility }\end{array}$ & $\begin{array}{l}\text { E5 } \\
\text { (Robustness) }\end{array}$ \\
\hline Computer Science D1 & & & & & \\
\hline Library and Information Sci. D2 & & & & & \\
\hline Telecommunication Science D3 & & & & & \\
\hline Electrical Engineering D4 & & & & & \\
\hline Civil Engineering D5 & & & & & \\
\hline Mechanical Engineering D6 & & & & & \\
\hline Mathematics D7 & & & & & \\
\hline Chemistry D8 & & & & & \\
\hline Physics D9 & & & & & \\
\hline Sociology D10 & & & & \\
\hline Accounting D11 & & & & \\
\hline
\end{tabular}

The summaries of data from the respondents were extracted to table 4. Table 7 forms the software standard overall rating across the selected Departments.

Table 7: Overall rating across the selected departments

\begin{tabular}{|l|l|}
\hline E-voting Software Standard & Score \\
\hline D1 & 0.4 \\
\hline D2 & 0.4 \\
\hline D3 & 0.4 \\
\hline D4 & 0.4 \\
\hline D5 & 0.6 \\
\hline D6 & 0.4 \\
\hline D7 & 0.4 \\
\hline D8 & 0.4 \\
\hline D9 & 7.0 \\
\hline D10 & 0.4 \\
\hline D11 & 0.6 \\
\hline
\end{tabular}

\section{DISCUSSION OF FINDINGS}

The overall results of students' evaluations of the e-voting software standard across the selected Departments were summarized in table 7 . In this table, the score value is synonymous to relative importance of each linguistic variable in table 3. The rating reflects the sampled opinion of students across eleven Departments in the University. The interpretation in table 3 shows that students from Departments 1,2,3,4,6,7,8 and 10 were of the opinion that the software developed for evoting is of minimum standard. Departments 5 and 11 rated the software as above minimum standard while in the opinion of Department 9, the software is of normal standard. Fuzzy logic is a powerful tool for evaluating performance in general as the flexibility of the model allows the decision maker to introduce vagueness, uncertainty, and subjectivity into the performance evaluation system. It is therefore, an ideal system when the decision maker is faced with series of sub-decisions.

\section{CONCLUSION AND RECOMMENDATION}

In this paper, a model for evaluating the standard of e-voting software using fuzzy logic technique is proposed. The result shows that the software developed for e-voting meets the minimum acceptable standard and capable of giving the decision maker a clear and flexible method of evaluating the software standard where the available data to be used for evaluation is based on vagueness and uncertainty. However, the evaluation shed light on the need to make some improvements. The model is recommended to be for evaluating the standard of software adopted for e-voting for the purpose of quality enhancement.

\section{REFERENCES}

[1] Hasanali, A., Abbas, N. A. and Hossein, N. (2011). Environmental Performance Evaluation Based on Fuzzy Logic, International Conference on Social Science and Humanity IPEDR vol.5. Singapore: IACSIT Press.

[2] Askerbeyli, I. N. and Abduljabar, J. S. (2011). Using fuzzy logic methods for carbon Dioxide control in carbonated beverages, International Journal of Electrical \& Computer Scienc, IJECS-IJENS 11(3), pp. 196-202.

[3] Feras, A. H., Mutaz, K. H. and Khairall, M. A. (2011). New applied e-voting system; Journal of Theoretical and Applied Information Technology, 25(2), ISSN: 1992-8645, pp. 88-97.

[4] Engels, G., Forster, A., Heckel, R. and Thone, S. (2008). Process Modeling using UML, Retrieved on $8^{\text {th }}$ December, 2012 from: http://www.itu.dk/courses/SMD/F2008/TH/EFHT05PAIS. pdf.

[5] Mendel, J. M. (2001). Uncertain Rule-Based Fuzzy Logic Systems: Introduction and New Directions, Prentice-Hall Publishing Company. ISBN: 978-0130409690.

[6] Komminist, W., Richard, A. K., and Adolfo, V. (2011). Formal analysis of an electronic voting system: An experience report. Journal of Systems and Software.

[7] Nurmi, H., Salomaa, A., and Santean, L. (1991). Secret ballot elections in computer networks. Computers and Security, 36 (10), pp. 553-560.

[8] ORG, (2007). Electronic Voting. A challenge to democracy? Retrieved on $7^{\text {th }}$ December, 2012 from http://www.openrightsgroup.org/uploads/org-evotingbriefing-pack-final.pdf

[9] Reza, B. (2005). Mobile Computing Principles: Designing and Developing Mobile Applications with UML and XML; New York: Cambridge University Press.

[10] Simon, B., Steve, M. and Ray, F. (2007). Object-Oriented Systems Analysis and Design using UML ( $3^{\text {rd }}$ ed.); $\mathrm{Mc}$ Graw Hill. 
[11] Susanne, C. (2010): E-voting handbook; Key steps in the implementation of e-enabled elections; Council of Europe, ISBN 978 92-871-6948-8.

[12] Tadayoshi, K., Adam, S., Aviel, D. R. and Dan, S. W. (2004). Analysis of an electronic voting system. IEEE Computer Society Press.

[13] Alvarez R.M , Hall, T.E and Trechsel, A.H. (2009): Internet Voting in Comparative Perspective: The Case of Estonia. JSOR 42(3), pp. 497-505, Retrieved on $28^{\text {th }}$ January, 2013 from : http://www.jstor.org/stable/3542534.
[14] Moyniha, D.P. (2004): Building Secure Elections: EVoting, Security, and Systems Theory. Public Administration Review, 64(5), pp. 515-52, Retrieved on $28^{\text {th }} \quad$ January, 2013 from http://www.jstor.org/stable/3542534.

[15] Schneier, B. (2003). Beyond Fear: Thinking Sensibly about Security in an Uncertain World. New York: Copericus Books. 